\title{
Narrative medicine to improve the management and quality of life of patients with COPD: the first experience applying parallel chart in Italy
}

This article was published in the following Dove Press journal: International Journal of COPD

\author{
Paolo Banfi' \\ Antonietta Cappuccio² \\ Maura E Latella ${ }^{3}$ \\ Luigi Reale ${ }^{2}$ \\ Elisa Muscianisi ${ }^{3}$ \\ Maria Giulia Marini² \\ 'Pneumological Rehabilitation, \\ IRCCS Fondazione Don Gnocchi \\ Onlus, Milan, Italy; ${ }^{2}$ Healthcare Area, \\ Fondazione ISTUD, Milan, Italy; \\ ${ }^{3}$ Medical Department, Novartis \\ Farma Spa, Origgio, Italy
}

\begin{abstract}
Purpose: Poor adherence to therapy and the failure of current smoking cessation programs demonstrate that the current management of COPD can be improved, and it is necessary to educate physicians about new approaches for taking care of patients. Parallel chart is a narrative medicine tool that improves the doctor-patient relationship by asking physicians to write about their patients' lives, thereby encouraging reflective thoughts on care.
\end{abstract}

Patients and methods: Between October 2015 and March 2016, 50 Italian pulmonologists were involved in the collection of parallel charts of anonymous patients with COPD. The narratives were analyzed according to the Grounded Theory methodology.

Results: In the 243 parallel charts collected, the patients (mean age 69 years, $68 \%$ men) are described as still active and as a resource for their families (71\%). The doctor-patient relationship started as difficult in 50\% of cases, and younger age and smoking were the main risk factors. The conversations turned positive in $78 \%$ of narratives, displaying deeper mutual knowledge, trust for the clinicians' ability to establish effective therapy (92\%), support efforts to quit smoking (63\%), or restore patients' activities $(78 \%)$.

Conclusion: All the physicians concurred that the adoption of innovative parallel charts was useful for improving clinical care and worthy of official inclusion in protocols for the management of COPD.

Keywords: narrative medicine, COPD, doctor-patient relationship, quality of life

\section{Introduction}

\section{Disease characteristics and implications}

COPD is a preventable and treatable chronic respiratory disease associated with several systemic effects and comorbidities that may contribute to its severity. ${ }^{1}$ COPD was the fourth leading cause of death worldwide in 2000, and figures suggest it will become the third leading cause by $2020 .^{2}$

The primary symptom of COPD is dyspnea, or breathlessness, which is perceived by patients as distressing, frightening, and often has a negative influence on quality of life and physical activity.,4 Studies suggest that COPD is perceived by patients as a disability ${ }^{5}$ and "not as a disease but as a health problem" related to lifestyle, and this perception has a negative impact on adherence to treatment. ${ }^{6}$

While a definitive cure for COPD does not yet exist, the disease can be adequately controlled through therapy and smoking cessation, especially if diagnosed in the early stages. However, adherence to treatment is extremely low, with rates of $<50 \%$ in Europe and America, and this has detrimental effects on patients' quality of life and
Correspondence: Antonietta Cappuccio Fondazione ISTUD, Piazza IV

Novembre 7, 2014 Milan, Italy

Tel +390323933801

Fax +390323933805

Email acappuccio@istud.it (c) 17 (5) 2018 Banfi et al. This work is published and licensed by Dove Medical Press Limited. The full terms of this license are available at https://www.dovepress.com/terms.php
and incorporate the Creative Commons Attribution - Non Commercial (unported, v3.0) License (http://creativecommons.org/licenses/by-nd $3.0 /$ ). By accessing the work you

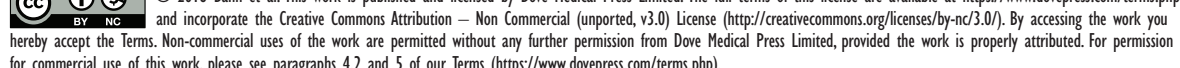


disease progression. ${ }^{7-9}$ In economic terms, valuable National Health Service resources are wasted due to the increased rate of relapses, hospitalizations, and related costs. ${ }^{10}$

Several studies have demonstrated the positive effects of a strong doctor-patient relationship and the benefits of good communication for patients' compliance with treatment. ${ }^{11-14}$ Such communication can help physicians overcome harmful patient preconceptions, beliefs, and low disease literacy that underlie resistance to treatment. ${ }^{15}$ The effectiveness of treatment is also influenced by patients' beliefs and choices regarding smoking. ${ }^{16,17}$ Literature shows that, despite contemporary antismoking strategies, $80 \%$ of patients relapse after 1 year. ${ }^{18,19}$ The only effective solution to prevent relapse seems to be support through counseling. ${ }^{19,20}$ In conclusion, the current management of COPD can be improved and it is necessary to educate physicians about new ways to manage their patients. ${ }^{21}$

\section{Narrative medicine: a novel approach for gaining insight}

Narrative medicine is a broad-spectrum approach for addressing the emotional and sociological aspects of persons affected by disease, and other stakeholders involved (health care professionals, caregivers, and family members). It originates in an analysis of the doctor-patient relationship through the evaluation of narratives collected from the parties involved. ${ }^{22}$ This practice aims to gain insight and provide an understanding of how a person lives with his/her illness, considering the many facets of the patient's care. ${ }^{23}$ In service of this goal, narrative medicine relies on the use of several narration tools: one of such tools conceived specifically for collecting physician feedback and narration is the "parallel chart". The parallel chart was first implemented in daily practice by Charon, ${ }^{24}$ and it is conceived as a space in which clinicians can collect their impressions in plain language as a supplement to the extremely technical and quantitative medical reports. ${ }^{24,25}$ The parallel chart facilitates reappraisal of the paradigm of patient care, expanding the physician's focus beyond clinical data to envision the person as a whole. ${ }^{26,27}$ The parallel chart is intended to be a private document where professionals can freely express their feelings toward patients, and they have the right to decide if they want to share their narration and with whom. ${ }^{24}$

The aim of the current study was to evaluate the doctorpatient relationship and its impact on patient life and care alliance. The second objective was to highlight the spheres of illness and sickness of COPD according to the perception of physicians. More broadly, this study aimed to gain knowledge of how to improve the quality of care through the use of parallel charts.

\section{Methods}

\section{Participants and study design}

From November 2015 to March 2016, 50 Italian pulmonologists participated in the study. Each physician was invited to attend a seminar on narrative medicine, and then write at least five parallel charts. The parallel chart included prompts that followed a semi-structured narrative plot representing a chronological series of events; prompts were included to help the clinicians overcome writer's block ${ }^{28}$ (Box 1). The parallel chart was created by a dedicated board composed of pulmonologists and experts in narrative medicine, particularly in research, who were also involved in the interpretation of the results. ${ }^{29}$ Clinicians had the choice to write the parallel chart with or without the prompts, but, to be eligible for the study, the personalized chart had to deal with 1) a relationship of the physician with a COPD patient who he/she had worked with for at least 6 months and 2) a patient who he/she has seen at least twice. Pulmonologists wrote the parallel chart after at least two visits and they could choose to write it immediately after the visit or later in the privacy of their own homes, which offered more time to write and reflect. There was no maximum or minimum length required for the narratives.

Narratives were collected through the Typeform online survey platform ${ }^{30}$ and at the end of the survey period, raw

Box I The semi-structured plot suggested for writing the parallel chart

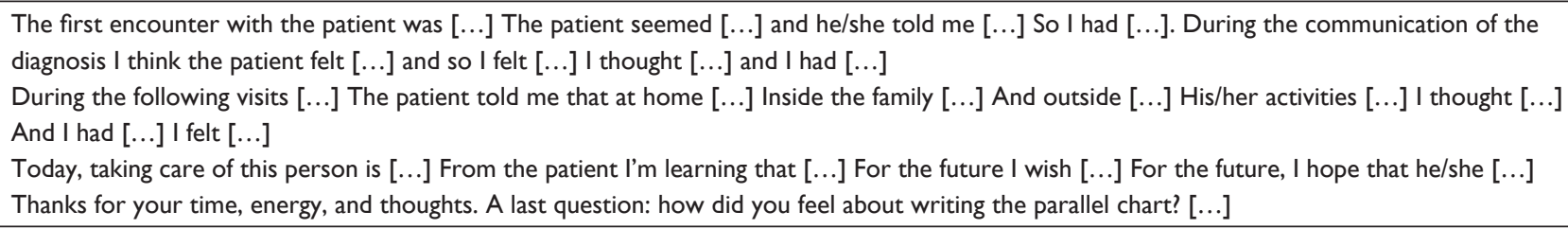

Note: For the purpose of accurate reporting, texts herein and in following boxes have been translated into English with a special effort to maintain the meaning as close as possible to the original, from both a linguistic and cultural point of view. The authors did the translation and the translation company T\&t SAS di Tina Attubato revised it. 
and anonymous data were downloaded as a Microsoft Excel spreadsheet. All data were self-reported and submitted anonymously. All narratives and instruments were written in Italian; the authors did the translation of the plot and the narratives extracts within the boxes and the translation company T\&t SAS di Tina Attubato revised it.

All pulmonologists informed their general managers about the study, signed the informed consent, and submitted anonymous data on their patients. The research was managed in accordance with the principles outlined in the Declaration of Helsinki. The Ethics Committee of Fondazione Don Gnocchi did not express an opinion because it considered our work as a consensus meeting report.

\section{Population size, data, and text analysis}

Sociodemographic variables were analyzed with descriptive statistics (mean, ranges, and classes), and frequencies were reported as percentages.

Narratives, written in the local language (Italian), were analyzed using the Grounded Theory approach ${ }^{31}$ for qualitative interpretation of texts. In order to reduce bias in their interpretation, analyses were conducted via triple-blind reading through three independent research phases. ${ }^{32}$ The first reading allowed us to define the cluster and the nodes for coding. The second reading was carried out with a specific qualitative data software program (QSR NVivo 10; QSR International, Melbourne, Australia), which enables thorough textual analysis of recurring words and semantic expressions, facilitating analyses of large volumes of narrative data. ${ }^{33,34}$

In addition to the Grounded Theory approach, a thematic analysis was carried out in accordance with the disease classification by the anthropologist Arthur Kleinman. ${ }^{35}$ Based on his definitions, three clusters of narratives were identified as follows: ${ }^{36}$

- “disease-centered" narratives - focused on the clinical and mechanistic point of view, with technical language and dry text which is not open to emotional considerations;

- "illness-centered" narratives - focused on living with a particular condition, with open language and narration that flows from an emotional, familiar, and social point of view;

- "sickness-centered" narratives - focusing on the external and publically visible aspects of living unhealthily.

This method, based on the Grounded Theory and classic narrative medicine classifications, has been used previously. ${ }^{28,36}$
Table I Personal details and profile of the 50 physicians involved in the study

\begin{tabular}{ll}
\hline Physician characteristics & $\begin{array}{l}\text { Physician } \\
\text { (N=50) }\end{array}$ \\
\hline Women, \% (n) & $42(21)$ \\
Men, \% $(n)$ & $58(29)$ \\
Mean age & $50($ min: 34, \\
& max: 65) \\
& $17($ min: I, \\
Professional years & max: 35$)$ \\
& \\
Region of origin, \% (n) & $40(20)$ \\
Northern Italy & $24(12)$ \\
Central Italy & $36(18)$ \\
Southern Italy & \\
Work setting, \% (n) & $50(25)$ \\
Working in a hospital & $38(19)$ \\
Working in a local public health care facility & $8(4)$ \\
Working in a private clinic & $4(2)$ \\
Working as private practitioner & \\
Specialization, \% (n) & $76(38)$ \\
Respiratory diseases & $12(6)$ \\
Internal medicine & $12(6)$ \\
Others & \\
Reason for choosing this specialization, \% (n) & $68(34)$ \\
Passion & $14(7)$ \\
Direct experience & $12(6)$ \\
Opportunity & $6(3)$ \\
Random &
\end{tabular}

\section{Results}

\section{Physicians' profile}

The study involved 50 Italian pulmonologists who wrote up a mean of 4.88 parallel charts each, for a total of 244 narratives on 244 people living with COPD, of which only one was excluded from the analysis because it was not intelligible. Clinicians spent, on average, 27 minutes writing one parallel chart. The sample of physicians consisted of $58 \%$ men, with a mean age of 50 years, which is representative of the population of Italian physicians. ${ }^{37}$ The study participants mainly came from the public health care sector, $76 \%$ specialized in respiratory diseases, $12 \%$ in internal medicine, and $12 \%$ in other disciplines; $68 \%$ had chosen their specialization because of their passion for the area (Table 1).

\section{The profile of the patients described by physicians}

The patients described in the parallel charts by participating physicians were mainly males $(68 \%)$ with a mean age of 69 years (Table 2). Among them, 70\% were married and only $14 \%$ of the narratives were about patients with no offspring, which is consistent with the statistics from the Italian Institute of Statistics (ISTAT) for this age group. ${ }^{38}$ Physicians described mainly patients with a high level of 
Table 2 Personal details and profile of the 243 patients described in the parallel charts

\begin{tabular}{ll}
\hline Patients' characteristics & Patients $\mathbf{( N = 2 4 3 )}$ \\
& $\%(\mathbf{n})$ \\
\hline Women & $32(78)$ \\
Men & $68(167)$ \\
Age & \\
$<54$ & $7(17)$ \\
$55-64$ & $22(54)$ \\
$65-74$ & $38(92)$ \\
$75-84$ & $26(63)$ \\
$\geq 85$ & $7(17)$ \\
Marital status & \\
Married & $70(140)$ \\
Widow/widower & $15(30)$ \\
Single & $9(18)$ \\
Divorced & $6(13)$ \\
Family status & \\
Children and grandchildren & $57(138)$ \\
Children & $22(53)$ \\
Nephews/nieces & $7(17)$ \\
No children or nephews/nieces & $14(34)$ \\
Education & \\
Primary school & $18(43)$ \\
Junior high school & $28(68)$ \\
High school & $37(90)$ \\
Bachelor's/Master's & $17(41)$ \\
Employment status & \\
Employed & $12(29)$ \\
Self-employed & $12(29)$ \\
Retired & $64(155)$ \\
Not working & $12(30)$ \\
Smoking habits & \\
Nonsmoker & $51(124)$ \\
Ex-smoker & $10(24)$ \\
Smoker at the first visit & $39(95)$ \\
\hline
\end{tabular}

education, which instead is not consistent with the ISTAT data for this age group. ${ }^{38}$ Twenty-four percent of patients still worked or were self-employed, and $49 \%$ of them were smokers or ex-smokers.

Patients mainly represented the second, third, and fourth stages of the Global Initiative for Chronic Obstructive Lung

Table 3 Onset of COPD and staging according to the functional classification of GOLD

\begin{tabular}{ll}
\hline Characteristics of the disease & Patients $(\mathbf{N}=\mathbf{2}$ I I) \\
\hline Mean age at diagnosis & $6 I(\min :$ I8, max: 85) \\
Years living with COPD & 9 (min: 0, max: 36) \\
Years treated by the current physician & $3.8(\min : 0$, max: 20) \\
Gold I, \% (n) & $3(6)$ \\
Gold II, \% (n) & $32(68)$ \\
Gold III, \% (n) & $37(78)$ \\
Gold IV, \% (n) & $28(59)$ \\
\hline
\end{tabular}

Abbreviation: GOLD, Global Initiative for Chronic Obstructive Lung Disease.
Table 4 Classification of the parallel charts among disease, illness, and sickness

\begin{tabular}{lllll}
\hline $\begin{array}{l}\text { Parallel charts } \\
(\mathbf{N}=\mathbf{2 4} \text { I) }\end{array}$ & IIIness & $\begin{array}{l}\text { IIIness and } \\
\text { disease }\end{array}$ & Disease & Sickness \\
\hline $\begin{array}{l}\text { Whole narrative, } \\
\%(n)\end{array}$ & 7I (I7I) & II (26) & I8 (43) & $22(53)$ \\
$\begin{array}{l}\text { Top I00 words } \\
\text { used for the } \\
\text { description of the } \\
\text { first encounter, \% }\end{array}$ & 43 & NA & 57 & NA \\
$\begin{array}{l}\text { Top I00 words } \\
\text { used for the } \\
\text { description of } \\
\text { the relationship } \\
\text { today, \% }\end{array}$ & & NA & 31 & NA \\
\hline
\end{tabular}

Abbreviation: NA, not applicable.

Disease functional classification system. ${ }^{17}$ They had lived with COPD for an average of 9 years, but pulmonologists had been treating them for an average of 4 years, since $\sim 50 \%$ of them were previously treated at other centers (Table 3 ).

\section{The language of parallel charts}

Analyzing the parallel charts in their entirety, the themes can be classified as illness-centered in $71 \%$ of the narratives, $18 \%$ describe only the disease, while $11 \%$ of the narratives present an integration of the two aspects. Sickness is present together with illness in $22 \%$ of the parallel charts and is mainly cited in reference to the issue of smoking and the use of oxygen therapy (Table 4).

By analyzing the 100 most frequently used words in the entire text of the 243 parallel charts, however, the terminology used belonged primarily to the sphere of the disease. By analyzing the 100 most frequently used words in the part of the narratives referring to the present relationship, in only $31 \%$ of cases pulmonologists used terms associated with the sphere of the disease, a significant decrease compared to those used for the description of the first encounter (57\%).

\section{Relationships with patients}

From the parallel charts, $80 \%$ of physicians actively listened to patients while trying to understand the needs of the person, while $20 \%$ stereotyped their patients (Table 5).

Table $\mathbf{5}$ Classification of the type of relationship established by physicians

\begin{tabular}{|c|c|}
\hline Type of relationship & $\begin{array}{l}\text { Doctor-patient relationship } \\
(\mathbf{N}=\mathbf{2 4 3}), \%(n)\end{array}$ \\
\hline Stereotyping & $20(49)$ \\
\hline Active listening & 80 (194) \\
\hline
\end{tabular}


Table 6 Relations with people with COPD "today" in the narratives, analyzed according to the age at diagnosis and their smoking habits

\begin{tabular}{|c|c|c|c|}
\hline Patients' characteristics & Easy, \% (n) & $\begin{array}{l}\text { Evolving from difficult } \\
\text { to easy, \% (n) }\end{array}$ & $\begin{array}{l}\text { Remained } \\
\text { difficult, \% (n) }\end{array}$ \\
\hline Overall narratives & $51(124)$ & $26(63)$ & $23(54)$ \\
\hline \multicolumn{4}{|l|}{ Patient age at diagnosis } \\
\hline$<45$ & $22(2)$ & $44(4)$ & $33(3)$ \\
\hline $45-54$ & $40(19)$ & $26(12)$ & $34(16)$ \\
\hline $55-64$ & $49(38)$ & $21(16)$ & $31(24)$ \\
\hline $65-74$ & $62(34)$ & $27(15)$ & $11(6)$ \\
\hline $75-85$ & $80(12)$ & $20(3)$ & - \\
\hline \multicolumn{4}{|l|}{ Smoking habits } \\
\hline Smoker & $15(5)$ & $12(4)$ & $74(25)$ \\
\hline Nonsmoker or ex-smoker & $62(90)$ & $24(35)$ & $14(20)$ \\
\hline Stopped smoking after the first visit & $47(29)$ & $39(24)$ & $15(9)$ \\
\hline
\end{tabular}

In $51 \%$ of the narratives, doctors described patients with whom the relationship had been easy from the first meeting, while for the remaining $49 \%$ the first visit was difficult. Throughout the duration of care, $26 \%$ of difficult relationships evolved into relationships based on trust and respect between the pulmonologist and the patient with COPD (Table 6). From the analysis of the narratives (explained in the "Age" and "Smoking" sections), the factors influencing the relationship were mainly the patients' smoking habits and age, while the quality of relationship impacted adherence and effectiveness of therapies, as well as the resumption of activities.

In terms of the language used by physicians, the parallel charts in which the doctor-patient relationship is described as evolving from difficult to easy contained both disease and illness-centered elements (Table 7). This blended language was not only more effective than the use of the disease-only terminology, but it also seemed to be more effective in being able to overcome a difficult relationship than the use of only the illness-centered style.

The doctor-patient relationship was not influenced by gender. The ability to change a difficult relationship into a

Table 7 Evolution of relationships (from difficult to easy, or difficult throughout), stratified by language classifications and by physician age

\begin{tabular}{lll}
\hline $\begin{array}{l}\text { Characteristics } \\
\text { related to physicians }\end{array}$ & $\begin{array}{l}\text { Evolving from difficult } \\
\text { to easy, \% (n) }\end{array}$ & $\begin{array}{l}\text { Remained } \\
\text { difficult, \% (n) }\end{array}$ \\
\hline $\begin{array}{l}\text { Language } \\
\text { Disease }\end{array}$ & $33(6)$ & $67(12)$ \\
Disease and illness & $69(11)$ & $31(5)$ \\
Illness & $55(46)$ & $45(37)$ \\
Physicians' age & & \\
$\quad<40$ & $33(8)$ & $67(16)$ \\
$40-50$ & $58(19)$ & $42(14)$ \\
$>50$ & $60(36)$ & $40(24)$ \\
\hline
\end{tabular}

positive one was less common in physicians under 40, who referred more to disease terminology (Table 7).

\section{Age}

Upon communication of the diagnosis of COPD, we observed a correlation between the patients' age and the evolution of the relationship: the beginning of the process was easier for older patients, whereas the percentage of relationships starting in a difficult manner increased with decreasing age (reaching $77 \%$ when people were $<45$ at the time of diagnosis; Table 6). From the analysis of the narratives, it appears that physicians faced more resistance in achieving acceptance of the disease from younger patients.

\section{Smoking}

From the analysis of the 92 parallel charts related to patients who were smokers, only $28 \%$ of health care professionals used an empathetic approach to encourage smoking cessation or refer patients to rehabilitation in antismoking centers. In $72 \%$ of cases, however, pulmonologists made use of threats, which were effective for $35 \%$ of patients and ineffective for the remaining $37 \%$. A total of $63 \%$ of patients stopped smoking while in care with the reporting physician (Box 2).

The type of doctor-patient relationship is strictly linked to the success in smoking cessation: the group of smokers who continued smoking despite the diagnosis of COPD had a difficult relationship with their pulmonologist in $74 \%$ of cases. The failure of the patients' smoking cessation led physicians to feel more distressed and irritated by such patients (Table 6).

Smoking was closely linked to the sphere of sickness, because patients were often described as being perceived 
Box 2 Example of extracts randomly selected by the researcher from the pool of parallel charts describing the smoking situation

\begin{tabular}{|c|c|}
\hline Smok & \\
\hline $\begin{array}{l}\text { "We talked a lot about what cigarettes meant to him and especially } \\
\text { the possible fear of having to quit because of health problems - } \\
\text { which were becoming important." } \\
\text { "I've prescribed him the same therapy but have changed the } \\
\text { trade name of the drug and, instead of imposing the care in an } \\
\text { authoritarian manner, I tried to use a more friendly and reassuring } \\
\text { approach, which eventually led him to promise a reduction of } \\
\text { cigarettes to } 10 \text { per day." }\end{array}$ & $\begin{array}{l}\text { "I suggest the patient have periodic checkups but above all to hold } \\
\text { to the intention of abstaining from smoking." The answer: "Doctor } \\
\text { I'm sure, after hearing what you told me, ie, that you do not assist } \\
\text { smokers, I would not have had the courage to come return to visit, } \\
\text { now or never." } \\
\text { "Several times in my life as a doctor, I thought back to that moment: } \\
\text { I do not know if it was me being very convincing, or if he was ready } \\
\text { and he just needed a confirmation of what he already knew, that } \\
\text { smoke had ruined his lungs." }\end{array}$ \\
\hline \multicolumn{2}{|l|}{ Smoking (nonfunctional threat) $37 \%$} \\
\hline \multicolumn{2}{|c|}{$\begin{array}{l}\text { "Are you still smoking!? Don't you understand that if you keep doing like this, you'll die next time? And who will take care of your granddaugh } \\
\text { I said, sounding a bit threatening. "What should I tell you Doctor? I can't ... I enjoy smoking too much to quit!! And then ... among my bridge } \\
\text { companions there is one who smokes more than me and is } 79 \text { years old! So ... why should everything come upon me?" } \\
\text { "For him smoking was unavoidable, he was not going to stop and explaining to him what could be the consequences of this choice served no } \\
\text { purpose. He knew it very well and really did not care!" }\end{array}$} \\
\hline
\end{tabular}

Note: For the purpose of accurate reporting, texts herein and in following boxes have been translated into English with a special effort to maintain the meaning as close as possible to the original, from both a linguistic and cultural point of view. The authors did the translation and the translation company T\&t SAS di Tina Attubato revised it.

as the "cause of their own disease" by both physicians and society: $66 \%$ of sickness narratives were related to patient smokers. The relationships that began with difficulties and anger led pulmonologists to not be willing to accept and understand the person they took care of, nor did it foster an effective path toward the containment or termination of the smoking addiction.

\section{Pharmacological treatments}

Reference to therapy was present in most parallel charts $(85 \%)$, while rehabilitation and respiratory physiotherapy were scarcely mentioned (only 10\% of charts). Efficacy of therapies was described in $73 \%$ of the narratives, $92 \%$ with a positive outcome (Box 3).

However, when the relationship was difficult, therapy was revealed to be ineffective or did not lead to an improvement perceived by patients in $44 \%$ of cases (Figure 1).
Forty-nine percent of the narratives mentioning therapy focused on adherence to treatment. On average, $80 \%$ of cases of adherence to treatment were mentioned, although this percentage varied depending on the quality of the doctor-patient relationship. When relationships were positive, all the patients achieved a "therapeutic alliance," while in cases of difficult relationships, $74 \%$ of patients did not comply with their prescriptions, mainly using drugs on an "as needed" basis.

\section{Activities}

Despite the mean age of patients being 69 years, patients were described in charts as still very active, full of interests, and often with an essential role in the family. Indeed, in $71 \%$ of the parallel charts physicians described the activities that patients had to give up or restrict because of their COPD symptoms (Box 4). These activities were divided among household activities, such as cooking and dressing (11\%),

Box 3 Example of extracts randomly selected by the researcher from the pool of parallel charts describing the therapies

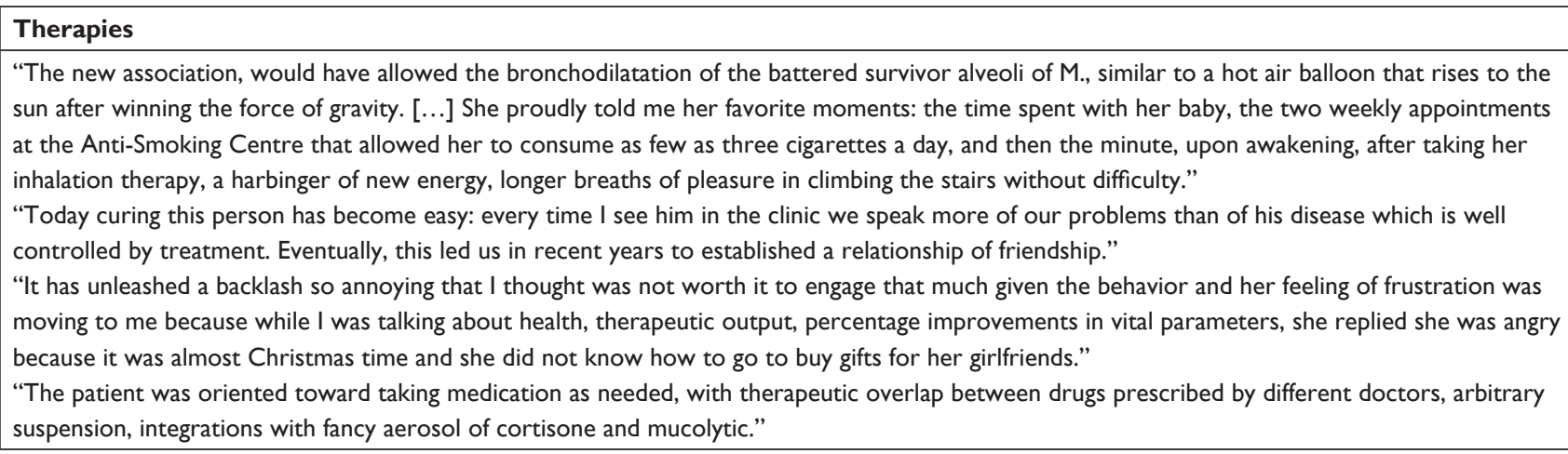

Note: For the purpose of accurate reporting, texts herein and in following boxes have been translated into English with a special effort to maintain the meaning as close as possible to the original, from both a linguistic and cultural point of view. The authors did the translation and the translation company T\&t SAS di Tina Attubato revised it. 

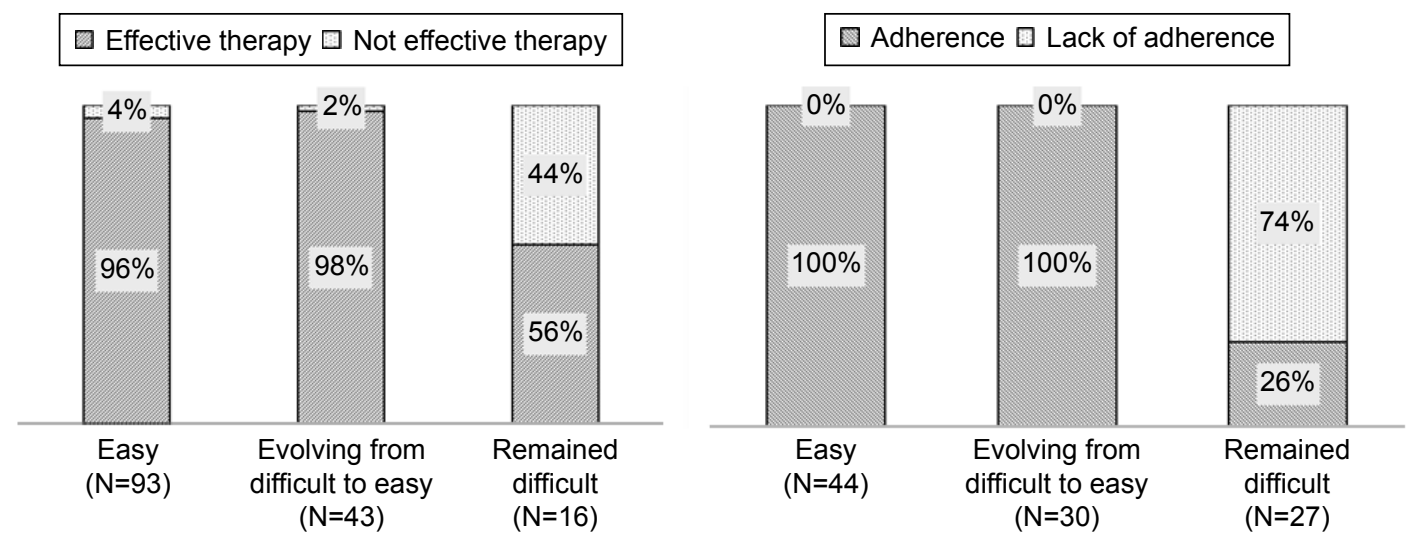

Figure I Effectiveness of therapies (on the left) and adherence to treatment (on the right) as reported within the narratives according to the difficulty of the relationship.

activities that involved leaving the house (59\%), such as gardening, work, city walks, shopping, exhibitions and theaters, and babysitting, or activities that required a high physical strain (30\%), such as sports or travel.

Thanks to the treatment and support of doctors, these activities were resumed in $78 \%$ of cases; however, this percentage dropped to $<35 \%$ in the subgroup burdened with a difficult relationship (Figure 2). Therefore, it is possible that the quality of the doctor-patient relationship has a direct impact on the ability to resume activities despite the disease; one possible explanation is the ability of physicians to identify and share patients' goals when the relationship is positive.

\section{Relationships with patients' family members}

The patient's family was mentioned in $75 \%$ of the 243 parallel charts (Box 5); 17\% of the patients lived alone. Relationships with lonely patients were often marked by sadness and tenderness, since physicians perceived their sense of loneliness and their need to be accepted and understood.
In $20 \%$ of the parallel charts, family members - often the patient's spouse - served as caregivers at the visits and actively intervened, speaking in place of or in addition to the patient. Their presence was sometimes welcomed by doctors, who considered the relative an ally whose contributions helped the physician to understand the patient's symptoms and possible targets for improvement; in other cases, the physician felt irritated by their intrusiveness. Relationships between patients and their family members were considered difficult in $22 \%$ of cases, while $61 \%$ of the patients with COPD could rely on a united and supportive family throughout treatment.

In $33 \%$ of the narratives, patients were in charge of taking care of grandchildren, disabled children, sick spouses, or "fragile" family members, which served as a stimulus for healing and improving COPD symptoms. For this group, being able to resume their caregiving activities was not only a personal need, but also a collective need for their entire family, since in their absence the role would have had to be performed by a paid professional.

Box 4 Example of extracts randomly selected by the researcher from the pool of parallel charts describing the activities

\footnotetext{
Activities

"The husband takes care of everything, treating her like a porcelain doll."

"She noticed that she could go shopping with less fatigue. She was taking her grandchildren to school and each time she felt happiness - as if it were the first time. Though, she had stopped traveling."

"He was a former heavy smoker, with a poor quality of life that prevented him to devote himself to his 'favorite' hobbies: the care of his garden and walking. [...] R.E. has not had exacerbations for a long time, he completes his gardening independently and above all he breathes without effort."

"When she came back one of the last times I saw her smile ... she was finally able to take a walk to the shopping streets without dyspnea; she told me that for some time she had been a normal person ..."

"The first time the patient had traveled with oxygen, he had felt uncomfortable; but then he saw other people (especially foreigners, he had noticed) travel despite the need for oxygen, wheelchairs, walkers or other and he had calmed down."
}

Note: For the purpose of accurate reporting, texts herein and in following boxes have been translated into English with a special effort to maintain the meaning as close as possible to the original, from both a linguistic and cultural point of view. The authors did the translation and the translation company T\&t SAS di Tina Attubato revised it. 


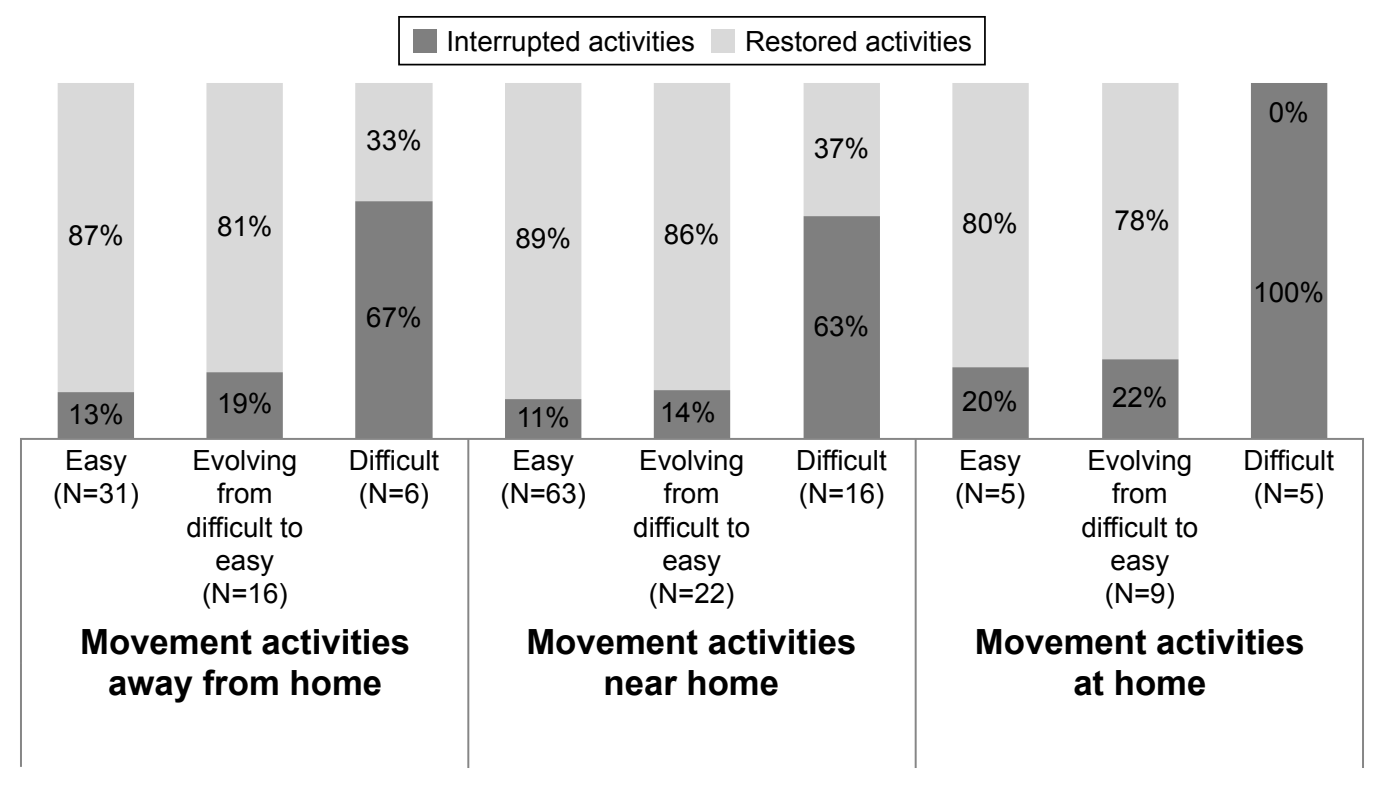

Figure 2 Restoration of activities according to the difficulty of the relationship.

\section{Physicians' experience of the parallel chart}

Sixty-five percent of physicians reported that they learned new aspects about their patients, thanks to the use of parallel chart (Box 6). Only 14\% of pulmonologists reporting learning about only clinical aspects, while the majority of doctors also reported learning about aspects such as empathy, strength, positivity, and the importance of family. Fifteen percent of physicians, despite having a difficult relationship with their patient, stated that they were better able to recognize her/his errors and limits through writing the narrative and were thus able to have a better prospective for handling similar situations in the future.

Secondly, $74 \%$ of physicians declared that this experience made them realize they would be interested in improving themselves and develop a greater capacity for listening and empathy. However, $6 \%$ would have preferred to have more time to dedicate to the visits, while $20 \%$ of pulmonologists desired some improvements from the scientific point of view.

In conclusion, the physicians involved in the project described the parallel chart as a positive experience through which they were able to reflect and obtain new knowledge to improve their relationships and management of care. In addition, $42 \%$ of pulmonologists said that writing was helpful and hoped to be able to continue to apply narrative medicine in their daily practice.

\section{Discussion}

Overall, this narrative experience was evaluated as positive by all of the participants, across specialties and professional age groups. The analysis of the feedback from physicians highlighted the usefulness of the parallel chart, as a narrative medicine tool, for encouraging the physicians to reflect on

Box 5 Example of extracts randomly selected by the researcher from the pool of parallel charts describing family relationship

Family relationship
"They did anything to not make him feel like a burden, even if he had to walk slowly or stop because of breathlessness."
"Everyone scolded her because she continued smoking."
"He had recently moved to his daughter's house to help her, as she had just separated from her husband, and was without a steady job, she would
have to take care of three children by herself."
"Slowly, arm in arm with her husband (who always accompanies her) the lady enters the ambulatory clinic in a very serene way."
"I remember the first time he came into the studio with his wife, who began to talk extensively about all her husband's problems while he was
sitting in silence. After about 30 minutes of monologue I got up and I asked the lady to sit on the couch for the visit. She answered, 'but the
sufferer is my husband,' and I still remember that he smiled."

Note: For the purpose of accurate reporting, texts herein and in following boxes have been translated into English with a special effort to maintain the meaning as close as possible to the original, from both a linguistic and cultural point of view. The authors did the translation and the translation company T\&t SAS di Tina Attubato revised it. 
Box 6 Example of extracts randomly selected by the researcher from the pool of parallel charts describing the reflections made by pulmonologists within this project

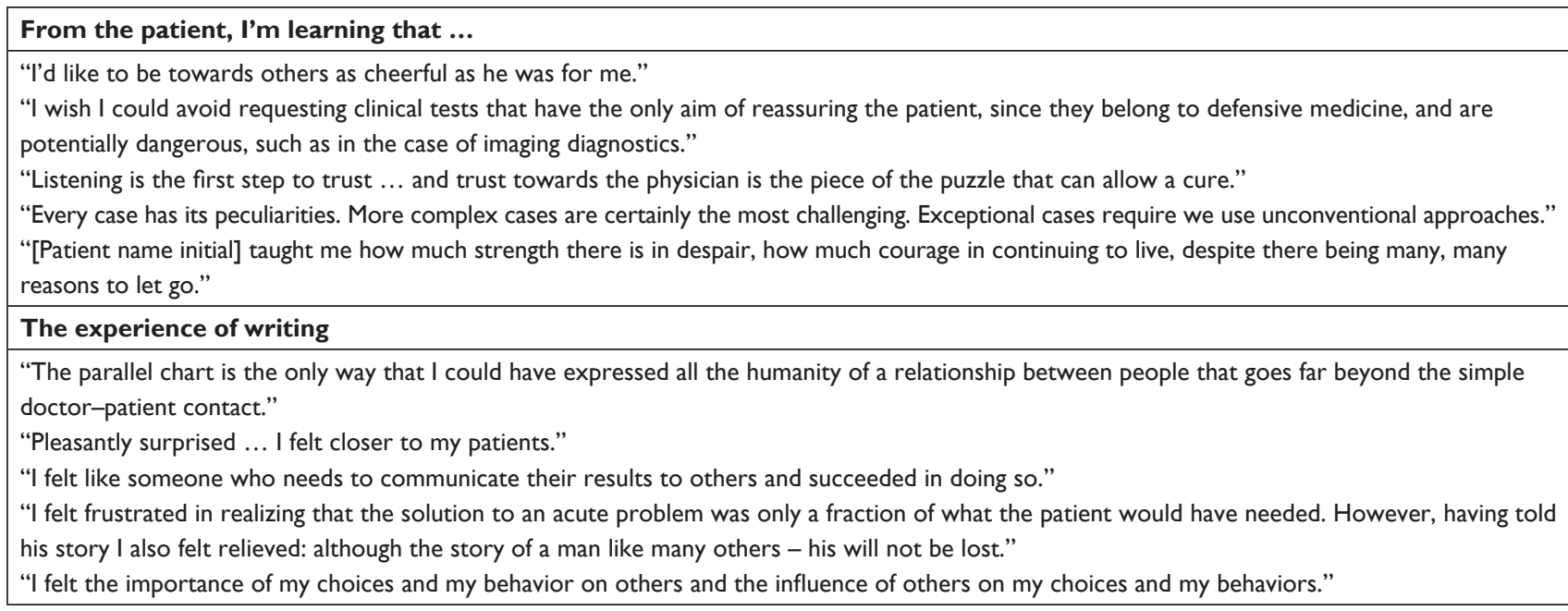

Note: For the purpose of accurate reporting, texts herein and in following boxes have been translated into English with a special effort to maintain the meaning as close as possible to the original, from both a linguistic and cultural point of view. The authors did the translation and the translation company T\&t SAS di Tina Attubato revised it.

their relationships with people with COPD. This tool allowed physicians to focus on key ways in which the relationship evolved in a positive or negative way, and gain insight on the true needs of patients. Reflective writing, in fact, has been demonstrated to help establish empathic doctor-patient relationships. ${ }^{39}$ It has already been included in several medical school training curricula, resulting in significant improvements in the physician's clinical practice. ${ }^{40}$ Unfortunately, writing requires time and, as reported in the results, physicians completed the parallel chart in 30 minutes on average. This means that it would be difficult to implement this tool in daily practice in Italy for all patients, due to practical time constrains. On the other hand, reflective writing could be implemented as a resource when pulmonologists have to deal with difficult cases to help them appreciate the critical importance of the relationship.

The study showed the significance of a linguistic (lexical and semantic) switch from a disease-centered description to a more patient-centered one. The issue of the language used by physicians with patients has been a relevant topic for $\sim 20$ years, and focused initially on the need for a change in the terminology used within routine checkup appointments, switching from disease-centered to more patient-centered medicine. ${ }^{41}$ Nevertheless, physicians are still struggling to avoid using technical terminology with their patients, and in some cases, this has proven to be an obstacle in the establishment/consolidation of the relationship with their patients. Indeed, our findings revealed that the physicians who used strictly disease-related terminology were those who reported the most difficult relationships with patients. Conversely, physicians who used both disease and illness-related terms in their narrations achieved the best results in overcoming difficult relationships. Furthermore, the parallel charts revealed a higher appreciation by patients of physicians who demonstrated both technical and empathic skills. Young pulmonologists (under 40) were found to have more difficulty in relating to patients than older clinicians: this could be explained by the strictly evidence-based medicine training carried out in recent years. ${ }^{42}$ As seen in Table 3, however, doctors have learned to use terminology more related to daily life. This change offers some proof of the fact that the writing of parallel charts helped doctors reflect on the lives of patients with COPD, as well as their own emotions and thoughts in relation to different situations.

According to our results, a critical factor in the doctorpatient relationship seemed to be patient smoking habits: smoking was perceived as the leading cause of sickness by doctors, who felt immediately uncomfortable when they had to treat a hard smoker. When the pulmonologist was able to overcome this initial discomfort, and listen to the patient, he or she was able to find a strategy to encourage the patient to end their dependence. In some cases, the most efficient strategy proved to be the use of threats; in other situations, patients were referred to smoking addiction rehabilitation centers, while others gained sufficient benefits from conversations with the doctor. These findings indicate that the same approach cannot be effective for (or imposed upon) all patients; rather, doctors should use dialogue and listening to identify the best approach for the individual. 
Finally, these findings identified a previously overlooked aspect of COPD treatment: patients who returned to being active and resumed their regular activities, despite initial difficulties related to the symptoms of the disease, showed higher adherence to treatment. There are a few previously published studies on patients' perception of COPD, but they all focus on a small number (10-15) of people with a severe form of the disease or who are in the acute phase. ${ }^{5,43-45}$

Analysis of the parallel charts also showed that better patient management is achieved when physicians are able to identify and share patient's personal goals, like being able to take care of their nephews or riding their bike. The ISTUD Foundation is currently conducting a follow-up study to better understand this aspect of pulmonologists' perception.

Within the narratives, the working environment or environmental risk factors were scarcely mentioned, whereas there was a strong focus on smoking habits. This result confirms the findings from another study in which patients stated that their pulmonologists focused only on their smoking as a triggering factor for COPD. ${ }^{5}$

A limitation of this study was the lack of direct testimonies from the patients with COPD about their illness experience, since only the physicians' point of view was recorded. The ISTUD Foundation is now completing another study that includes the voices of patients with COPD and their caregivers. ${ }^{46}$ On the other hand, this study is innovative and particularly important considering that most studies in narrative medicine collect narratives from patients rather than from physicians. Therefore, this study represented a precious opportunity to obtain a snapshot of the current perceptions of Italian pulmonologists, although they may not be a nationally representative sample. ${ }^{47}$ The parallel charts allowed us to understand how physicians reason, feel, and act when caring for patients with COPD, providing useful suggestions for possible areas of improvement.

\section{Conclusion}

This study showed that a positive relationship based on listening and understanding can help patients be more adherent to treatment, improve their lifestyle, resume activities that were interrupted because of failing health, and improve their quality of life. Doctors who are able to go beyond the strictly clinical aspects of care and to accept and understand people with COPD can limit the barriers to treatment and achieve satisfying results in the form of improved treatment adherence.

\section{Acknowledgments}

The authors are grateful to all the pulmonologists who participated in the project and wrote their parallel charts: Abello Paola, Agneni Maria Luisa, Aiello Marina, Alfieri Antonio, Ambrosino Annamaria, Andreani Maria Rita, Aprea Roberto, Arcoleo Giuseppe, Balestrino Antonella, Bastianelli Angelo, Bertucci Leonardo, Biagini Marco, Bonacci Eleonora, Bonacina Cristiano, Bonavia Marco, Cagnazzo Maria Grazia, Cannata Enzo, Cortorillo Giuseppe, D'Amato Mariella, D'Angeli Annalisa, D'Antonio Cristian, De Conti Fabio, De Simone Giuseppe, Di Simone Salvatore, Fantoni Umberto, Forlani Sara, Fumagalli Alessia, Giorio Sonia, Giuliani Antonio, Guadalupi Giovanni, Guerra Simona, Launaro Nicola, Leonetti Luigi, Madaschi Claudia, Marino Gaspare, Martino Laura, Olori Giacomina, Pabani Rita, Petrò Emiliano, Pietrangeli Vittorio, Piro Roberto, Polverino Antonio, Puorto Antonella, Rossella Cifaldi, Salis Stefano, Siscaro Gherardo, Sorrentino Luigi, Tazza Roberto, and Villari Liliana. The authors are grateful to Manuella Walker (Pencil and Papers, Italy) for the editing of the manuscript.

\section{Disclosure}

This project was sponsored by Novartis Farma, Italy. The funder provided financial support to the research since Fondazione ISTUD is a non-profit organization and its work is funded by private or public grant. The funders had no role in data collection and analysis and in the decision to publish this study. Furthermore, the funder provided support in the form of salaries for authors EM and MEL, but did not have any additional role in the study design, data collection and analysis, decision to publish, or preparation of the manuscript. The authors report no other conflicts of interest in this work.

\section{References}

1. Nazir SA, Erbland ML. Chronic obstructive pulmonary disease. Drugs Aging. 2009;26(10):813-831.

2. Sin DD, Anthonisen NR, Soriano JB, Agusti AG. Mortality in COPD: role of comorbidities. Eur Respir J. 2006;28(6):1245-1257.

3. Han J, Dai L, Zhong N, Young D. Breathlessness or health status in chronic obstructive pulmonary disease: the impact of different definitions. COPD. 2015;12(2):115-125.

4. Carel H, Macnaughton J, Dodd J. Invisible suffering: breathlessness in and beyond the clinic. Lancet Respir Med. 2015;3(4):278-279.

5. McMillan Boyles C, Hill Bailey P, Mossey S. Chronic obstructive pulmonary disease as disability: dilemma stories. Qual Health Res. 2011;21(2):187-198.

6. Pinnock H, Kendall M, Murray SA, et al. Living and dying with severe chronic obstructive pulmonary disease: multi-perspective longitudinal qualitative study. BMJ. 2011;342:d142.

7. Bourbeau J, Barlett SJ. Patient adherence in COPD. Thorax. 2008;63(9): 831-838. 
8. Agh T, Inotai A, Meszaros A. Factors associated with medication adherence in patients with chronic obstructive pulmonary disease. Respiration. 2011;82(4):328-334.

9. Blasi F, Raddi F, Miravitlles M. Interactive monitoring service and COPD: is it possible to reduce nonadherence? COPD. 2015;12(3):227-233.

10. Blanchette CM, Gutierrez B, Ory C, Chang E, Akazawa M. Economic burden in direct costs of concomitant chronic obstructive pulmonary disease and asthma in a Medicare Advantage population. JManag Care Pharm. 2008;14(2):176-185.

11. Santus P, Picciolo S, Proietto A, et al. Doctor-patient relationship: a resource to improve respiratory diseases management. Eur J Intern Med. 2012;23(5):442-446.

12. Kale MS, Federman AD, Krauskopf K, et al. The association of health literacy with illness and medication beliefs among patients with chronic obstructive pulmonary disease. PLoS One. 2015;10(4):e0123937.

13. Laforest L, Denis F, Van Ganse E, et al. Correlates of adherence to respiratory drugs in COPD patients. Prim Care Respir J. 2010;19(2): $148-154$.

14. Krauskopf K, Federman AD, Kale MS, et al. Chronic obstructive pulmonary disease illness and medication beliefs are associated with medication adherence. COPD. 2015;12(2):151-164.

15. Gysels M, Higginson IJ. The experience of breathlessness: the social course of chronic obstructive pulmonary disease. J Pain Symptom Manage. 2010;39(3):555-563.

16. George J, Kong D, Thoman R, Steward K. Factors associated with medication nonadherence in patients with COPD. Chest. 2005;128(5): 3198-3204.

17. Global initiative for Chronic Obstructive Lung Disease. GOLD 2017 Global strategy for the diagnosis, management and prevention of COPD. Available from http://goldcopd.org/gold-2017-global-strategy-diagnosis-management-prevention-copd/. Accessed December 13, 2017.

18. Tashkin DP, Rennard S, Hays JT, Ma W, Lawrence D, Lee TC. Effects of varenicline on smoking cessation in patients with mild to moderate COPD: a randomized controlled trial. Chest. 2011;139(3): 591-599.

19. Tashkin DP. Smoking cessation in chronic obstructive pulmonary disease. Semin Respir Crit Care Med. 2015;36(4):491-507.

20. AHRQ. Treating tobacco use and dependence: 2008 update (content last reviewed June 2015). Rockville, MD: Agency for Healthcare Research and Quality. Available from: http:/www.ahrq.gov/professionals/ clinicians-providers/guidelines-recommendations/tobacco/index.html. Accessed November 24, 2017.

21. Leiva-Fernández J, Leiva-Fernández F, García-Ruiz A, Prados-Torres D, Barnestein-Fonseca P. Efficacy of a multifactorial intervention on therapeutic adherence in patients with chronic obstructive pulmonary disease (COPD): a randomized controlled trial. BMC Pulm Med. 2014;14(1):1-12.

22. Greenhalgh T. Narrative based medicine: narrative based medicine in an evidence based world. BMJ. 1999;318(7179):323-325.

23. Marini MG. Narrative Medicine: Bridging the Gap between EvidenceBased Care and Medical Humanities. 1st ed. New York: Springer International Publishing; 2016.

24. Charon R. Narrative medicine in the international education of physicians. Presse Med. 2013;42(1):3-5.

25. Charon R. The patient-physician relationship. Narrative medicine: a model for empathy, reflection, profession, and trust. JAMA. 2001; 286(15):1897-1902.

International Journal of COPD

\section{Publish your work in this journal}

The International Journal of COPD is an international, peer-reviewed journal of therapeutics and pharmacology focusing on concise rapid reporting of clinical studies and reviews in COPD. Special focus is given to the pathophysiological processes underlying the disease, intervention programs, patient focused education, and self management protocols.
26. Langellier KM. Performing narrative medicine. J Appl Commun Res. 2009;37(2):151-158.

27. Clandinin DJ, Cave M-T. Creating pedagogical spaces for developing doctor professional identity. Med Educ. 2008;42(8):765-770.

28. Marini MG, Reale L, Cappuccio A, et al. Narrative medicine to highlight values of Italian pain therapists in a changing healthcare system. Pain Manag. 2014;4(5):351-362.

29. Greenhalgh T. Cultural Contexts of Health: The Use of Narrative Research in the Health Sector. Health evidence network synthesis report, no. 49. Copenhagen: WHO Regional Office for Europe; 2016. Available from: https://www.ncbi.nlm.nih.gov/books/NBK391066/. Accessed December 13, 2017.

30. Typeform survey platform. Available from: https://www.typeform.com/. Accessed December 13, 2017.

31. Glaser BG, Strauss AL, Strutzel E. The discovery of grounded theory; strategies for qualitative research. Nurs Res. 1968;17(4):364.

32. Duque RL. Review: Catherine Kohler Riessman (2008). Narrative methods for the human sciences. Forum Qual Soc Res. 2010;11(1):2907.

33. Welsh E. Dealing with data: using NVivo in the qualitative data analysis process. Forum Qual Soc Res. 2002;3(2):1881.

34. Basit T. Manual or electronic? The role of coding in qualitative data analysis. Educ Res. 2003;45(2):143-154.

35. Kleinman A, editor. The illness narrative, suffering, healing and the human condition. New York: Basic Book; 1989.

36. Cappuccio A, Limonta T, Parodi A, et al. Living with chronic spontaneous urticaria in Italy: a narrative medicine project to improve the pathway of patient care. Acta Derm Venereol. 2017;97(1):81-85.

37. National statistics on state employee [cited June 8, 2016]. Available from: http://www.contoannuale.tesoro.it/. Accessed June 8, 2016.

38. ISTAT website [cited June 8, 2016]. Available from: http://www.istat. it/it/files/2015/12/C07.pdf. Accessed December 13, 2017.

39. DasGupta S, Charon R. Personal illness narratives: using reflective writing to teach empathy. Acad Med. 2004;79(4):351-356.

40. Chen I, Forbes C. Reflective writing and its impact on empathy in medical education: systematic review. J Educ Eval Health Prof. 2014; $11: 20$.

41. Moja EA, Vegni E. La medicina centrata sul paziente [Patient-centered medicine]. Ann Ital Med Int. 1998;13(1):56-64. Italian.

42. Hojat M, Vergare MJ, Maxwell K, et al. The devil is in the third year: a longitudinal study of erosion of empathy in medical school. Acad Med. 2009;84(9):1182-1191.

43. Kvangarsnes M, Torheim H, Hole T, Öhlund LS. Narratives of breathlessness in chronic obstructive pulmonary disease. J Clin Nurs. 2013 ; 22(21-22):3062-3070.

44. Ek K, Ternestedt BM, Andershed B, Sahlberg-Blom E. Shifting life rhythms: couples' stories about living together when one spouse has advanced chronic obstructive pulmonary disease. J Palliat Care. 2011; 27(3):189-197.

45. Bailey PH. The dyspnea-anxiety-dyspnea cycle-COPD patients' stories of breathlessness: "It's scary/when you can't breathe". Qual Health Res. 2004;14(6):760-778.

46. Gatti V, Amaducci S, Banfi P, et al. FARO: Far luce attraverso i racconti di persone con BPCO sul loro vissuto. Poster presented at: Progresso e Innovazione Tecnologica in Pneumologia. XLIV Congresso Nazionale della Pneumologia Italiana - AIPO; June 10-13; 2017; Bologna, Italy.

47. Bury M. Illness narratives: fact or fiction? Sociol Health Ill. 2001; 23(3):263-285.

\section{Dovepress}

This journal is indexed on PubMed Central, MedLine and CAS. The manuscript management system is completely online and includes a very quick and fair peer-review system, which is all easy to use. Visit http://www.dovepress.com/testimonials.php to read real quotes from published authors. 